\title{
A comparison of intramuscular ketamine with high dose intramuscular midazolam with and without intranasal flumazenil in children before suturing
}

\author{
R McGlone, T Fleet, S Durham, S Hollis
}

\begin{abstract}
Objectives-(a) To compare the use of high dose intramuscular midazolam with and without intranasal flumazenil in children after suturing. (b) To compare the use of high dose intramuscular midazolam with low dose intramuscular ketamine in children before suturing.

Methods-87 children, aged between 1 and 7 years, presenting with simple wounds needing sedation, were studied. Children considered combative $(n=47)$ were given ketamine $(2.5 \mathrm{mg} / \mathrm{kg}$ intramuscularly). The remaining 40 children were given midazolam ( $0.4 \mathrm{mg} / \mathrm{kg}$ intramuscularly) with and without flumazenil (25 $\mu \mathrm{g} / \mathrm{kg}$, intranasally).

Results-The median oxygen saturation was $97 \%$ in both midazolam groups. Flumazenil significantly reduced the amount of agitation during recovery $(p=0.048)$ and also the time at which children were ready for discharge (median 55 versus 95 minutes, $p$ value $<0.001)$. After discharge both midazolam groups had an unsteady gait (75\%) and there was no significant difference in the duration. As expected because of the deliberate selection of combative children into the ketamine group, the pre-sedation behaviour was slightly more disturbed compared with the midazolam group $(\mathrm{p}=0.10)$. However, the ketamine group was less agitated during local anaesthetic and suturing p $<0.001$.
\end{abstract}

Conclusion-Intramuscular midazolam $(0.4 \mathrm{mg} / \mathrm{kg})$ did not effectively sedate the children, in that a significant number still had to be restrained. However, none could remember the suturing. Intranasal flumazenil seems to be effective in shortening the time to discharge. If midazolam is to be used then a dose high enough to produce full amnesia should be used, there seems to be no advantage in increasing the dose further. Low dose intramuscular ketamine remains the drug of choice.

(Emerg Med f 2001;18:34-38)

Keywords: suturing; children; midazolam; intranasal flumazenil; ketamine

Suturing of children in accident and emergency $(\mathrm{A} \& \mathrm{E})$ can be distressing not only for the child, but for parents, nurses and doctors alike. Some children will cooperate with suturing, if time is spent explaining the procedure and distraction techniques are used. However, many remain terrified and for these children future visits to the accident department or GP's surgery often precipitate screams of protestation.

We have previously ${ }^{1}$ demonstrated that intramuscular ketamine reduces distress during suturing of children compared with intranasal midazolam. However, there is still a reluctance to use ketamine in the United Kingdom and there are contraindications for the use of ketamine, ${ }^{1}$ in particular it should not be given if the child has a current upper respiratory tract infection or active asthma. In view of this we decided to study the use of intramuscular midazolam in selected children and investigate the additional effect of intranasal flumazenil. Flumazenil was used in view of the potential for prolonged sedation when using a relatively high dose for midazolam. Midazolam for sedation has now an established role for this particular clinical problem and has been extensively used. ${ }^{2-6}$

Flumazenil, an imidazobenzodiazepine, is a specific competitive inhibitor for benzodiazepines such as midazolam. The drug has been used via various routes effectively. Studies into the intravenous, intramuscular (im), or oral routes found all three to be effective. ${ }^{78}$ It has also been used rectally ${ }^{9}$ and intranasally. ${ }^{10}$ Intranasal administration is not a contraindicated route.

Midazolam has been used extensively intravenously in the UK in adult $A \& E$ practice, before the reduction of fractures and dislocations. In UK paediatric practice the oral form has been used, ${ }^{25}$ however the onset of action and effect is very variable and unpredictable. Oral midazolam is subject to first pass metabolism and incomplete absorption, which causes the dosing to be higher than other routes. ${ }^{1}$ Intranasal use causes a burning sensation, which can be distressing to the child. ${ }^{11}$

The drug has a licence for intramuscular use and the bioavailability of intramuscular midazolam is high approximately $87 \% .{ }^{12}$ We proposed to use a dose of $0.4 \mathrm{mg} / \mathrm{kg} \mathrm{im}$ in an attempt to reduce the amount of restraint needed as this dose was higher than any previous study. The drug has a good safety record, however it is capable of respiratory depression, therefore monitoring is essential and flumazenil should be available. As in the adult the drug 
does have a useful amnesic effect in children. $^{213}$

\section{Methods}

SUBJECTS

Children attending the department with lacerations were entered for the study if they were aged between 12 months and 7 years and the examining doctor considered sedation necessary. Children were excluded if the laceration was complicated by more serious injury such as bone fracture or a closed head injury associated with loss of consciousness. Those who had recently eaten (full meal within three hours) ${ }^{114}$ were asked either to wait or attend the department later.

PROCEDURE

All children had the procedure done by a senior $\mathrm{A} \& \mathrm{E}$ doctor with a trained $\mathrm{A} \& \mathrm{E}$ nurse present throughout.

In view of our previous results ${ }^{1}$ it was considered unethical to withhold ketamine if the child was combative. Thus all children judged by the treating doctor to be combative (agitated/crying) were given ketamine (2.5 $\mathrm{mg} / \mathrm{kg}$ im with atropine $0.01 \mathrm{mg} / \mathrm{kg} \mathrm{im}$ ).

After informed consent from the parent, the remaining children were allocated sequentially to treatment groups. The first 20 children received only intramuscular midazolam and the next 20 also received intranasal flumazenil. Parents were given a fact sheet on the drugs given, which included guidance for when the child was discharged.

Both midazolam groups were given 0.4 $\mathrm{mg} / \mathrm{kg}$ im $(5 \mathrm{mg} / \mathrm{ml})$ into outer aspect of the thigh. Infiltration of local anaesthetic occurred after at least five minutes had passed.

The procedure took place in the $\mathrm{A} \& \mathrm{E}$ theatre with resuscitation, suction equipment and oxygen available. Monitoring was done with pulse oximetry. Parents were encouraged to stay with their child during the procedure.

After the suturing the flumazenil group was given $(25 \mu \mathrm{g} / \mathrm{kg})$ slowly intranasally up to $2 \mathrm{ml}$ at a time (maximum $5 \mathrm{ml}$ ).

During recovery the child was placed on their side. The child was observed until they returned to their baseline level of awareness and verbalisation.

OBSERVATIONS

During the procedure oxygen saturation was monitored continuously, the lowest oxygen saturation on the trend graph (on the Propaq display) was documented.

Behaviour before the procedure, during the infiltration of local anaesthetic and during suturing was rated on a 4 point scale ${ }^{1}$ by the nurse as either: (1) cooperative or sleeping; (2) intermittent crying or fighting; (3) continuous crying or fighting; (4) uncontrolled crying or fighting.

If any restraint was needed the nurse would document whether head, arms and/or legs were restrained and the total number of areas restrained (0-3). Reaction of parents during procedure was documented as either showing no response or feeling faint or upset.
If any respiratory difficulty occurred then this was documented along with any intervention.

Difficulty in administration of the intranasal flumazenil was recorded. Any vomiting was noted either during the procedure or in recovery.

The doctor recorded the site of the laceration, the length, the number of sutures and whether it was closed in one layer.

During recovery, the behaviour of the child was documented by the nurse on a 4 point scale $^{1}$. (0) Quiet and uneventful; (1) mild agitation; (2) moderate agitation; (3) pronounced agitation.

DISCHARGE CRITERIA

The child had to be able to recognise his or her parents, demonstrate purposeful motor activity and be able to walk unaided. Parents were instructed that their child should not walk independently for the first two hours after discharge and only clear fluids should be allowed during this time.

\section{FOLLOW UP}

Parents were contacted by telephone by medical staff within 24 to 72 hours to complete a questionnaire. If they were not on the phone then they were given a stamped addressed envelope with the questionnaire to complete.

Did your child have any vomiting after leaving hospital?

Did your child experience any nightmares? If so when?

For how long did you supervise your child after returning home?

Was his/her walking unsteady? If so for how long?

Was your experience in accident and emergency worse, same or better than expected?

Does your child remember the suturing when asked?

The project was passed by the Lancaster, Kendal and South Lakes Research Ethics Committee.

STATISTICAL METHODS

Most data, including all scores and times, could not be assumed to be normally distributed and were analysed using Mann-Whitney tests to compare groups. Age, weight and number of sutures were reasonably normally distributed and were compared between groups using unpaired $t$ tests. $\chi^{2}$ Tests were used to compare proportions of dichotomous variables.

\section{Results}

During the course of the study 47 children were judged combative and given intramuscular ketamine $(2.5 \mathrm{mg} / \mathrm{kg}$ im with atropine 0.01 $\mathrm{mg} / \mathrm{kg} \mathrm{im})$. The characteristics of the three patient groups ketamine, midazolam and midazolam + flumazenil are shown in table 1 . No children were excluded from the study once entered. 
Table 2 Recovery behaviour

\begin{tabular}{lll}
\hline & Midazolam & $\begin{array}{l}\text { Midazolam and } \\
\text { flumazenil }\end{array}$ \\
\hline Quiet and uneventful (\%) & $8(40)$ & $15(75)$ \\
Mild agitation (\%) & $6(30)$ & $2(10)$ \\
Moderate agitation (\%) & $3(15)$ & $1(5)$ \\
Pronounced agitation (\%) & $3(15)$ & $2(10)$ \\
\hline $\mathrm{p}=0.048$. & &
\end{tabular}

COMPARISON OF THE USE OF HIGH DOSE INTRAMUSCULAR MIDAZOLAM WITH AND WITHOUT INTRANASAL FLUMAZENIL IN CHILDREN AFTER SUTURING

There was no difficulty in administration of the intranasal flumazenil at the end of the procedure, although in view of the volume given this had to be done slowly. The child's level of consciousness would typically improve between 5 and 10 minutes after the drug was given.

Recording of oxygen saturation was problematic in the midazolam group as children who were inadequately sedated would make repeated attempts to remove the oximetry probe. The lowest recorded oxygen saturation for the midazolam group was $88 \%$ (during a crying bout) and the next lowest was $92 \%$. The median value was $97 \%$ in both groups $(\mathrm{p}=0.24)$.

In view of the known problem of agitation with midazolam ${ }^{1}$ we were anxious to study this aspect. Flumazenil significantly reduced the amount of agitation during recovery $(p=0.048$, table 2) and reduced the time from the start of the procedure to discharge (medians 55 versus 95 minutes, $\mathrm{p}<0.0001$, fig 1 ). One 4 year old child in the flumazenil group was discharged after 145 minutes at 2305. Either the child was more sensitive to the effect of midazolam or he was simply sleeping naturally as it was late at night.

Follow up questionnaires were completed in all cases. An unsteady gait after the procedure was expected, however this was sometimes difficult to quantify if the child was discharged late at night and due to go to bed. Unsteady gait was noted in both the midazolam and midazolam with flumazenil groups (both $75 \%$ ) and resolved within two to three hours in both groups $(p=0.71)$

The question regarding how long the child was supervised for was included to assess parental anxiety. The median times in the midazolam and midazolam with flumazenil group were 3.0 and 4.3 hours respectively $(p=0.71)$. If the child was discharged late at night then the parent would often sleep with him or her.

Table 1 Characteristics of patients and their wounds

\begin{tabular}{llllll}
\hline Number & & & $\begin{array}{l}\text { Midazolam }+ \\
\text { flumazenil 20 }\end{array}$ & $\begin{array}{l}\text { Significance } \\
\text { Kv } \pm \pm F\end{array}$ & $\begin{array}{l}\text { Significance } \\
\text { Mv } M+F\end{array}$ \\
\hline Age (y) & $3.7(2.3)$ & $3.4(1.7)$ & $2.9(1.4)$ & $\mathrm{p}=0.13$ & $\mathrm{p}=0.32$ \\
Weight (kg) & $18.8(8.2)$ & $16.6(4.9)$ & $16.1(4.6)$ & $\mathrm{p}=0.08$ & $\mathrm{p}=0.76$ \\
Facial wounds (\%) & $29(62)$ & $15(75)$ & $13(65)$ & $\mathrm{p}=0.42$ & $\mathrm{p}=0.49$ \\
Size of wound (cm) & $2.6(1.3)$ & $1.8(0.4)$ & $2.2(0.7)$ & $\mathrm{p}=0.01$ & $\mathrm{p}=0.06$ \\
Single layer closure (\%) & $30(64)$ & $16(80)$ & $18(90)$ & $\mathrm{p}=0.03$ & $\mathrm{p}=0.38$ \\
Number of sutures & $5.9(2.8)$ & $4.1(1.7)$ & $4.2(1.5)$ & $\mathrm{p}<0.001$ & $\mathrm{p}=0.85$ \\
\hline
\end{tabular}

Values are mean (SD) or number (percentage).

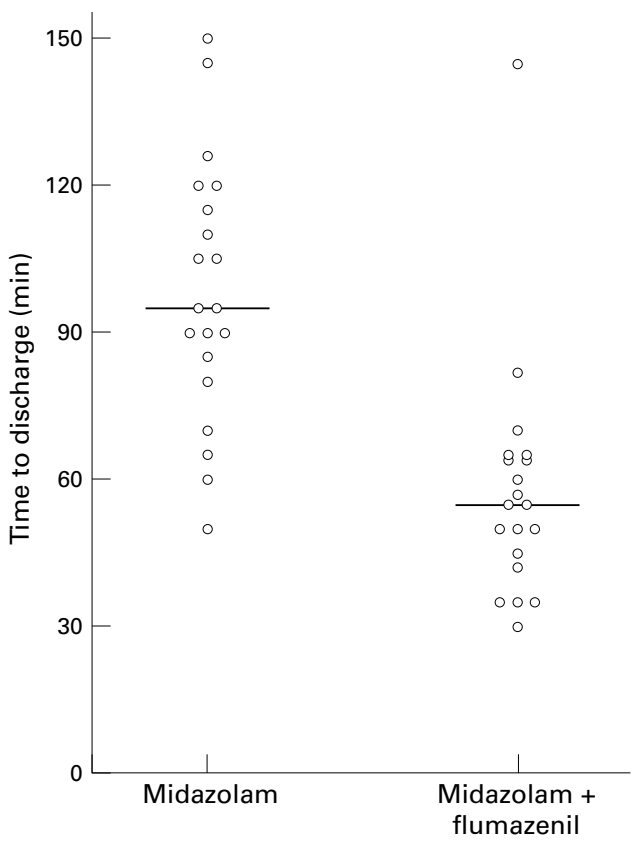

Figure 1 Comparison of time of discharge from start of procedure.

In the midazolam group one child vomited during recovery and in the midazolam with flumazenil group two vomited at home.

COMPARISON OF THE USE OF HIGH DOSE INTRAMUSCULAR MIDAZOLAM WITH LOW DOSE INTRAMUSCULAR KETAMINE IN CHILDREN BEFORE SUTURING

Two children required a second dose of ketamine $(1 \mathrm{mg} / \mathrm{kg} \mathrm{im})$ to achieve adequate sedation.

As expected because of the deliberate selection of combative children into the ketamine group, the pre-sedation behaviour was slightly more disturbed in this group $(\mathrm{p}=0.10)$. However despite this, the ketamine group was less agitated during local anaesthetic and suturing $\mathrm{p}<0.001$ (fig 2).

Restraint was measured 0 to 3 indicating the number of body parts restrained. Despite the midazolam group excluding the combative children, more restraint was still needed in this group during both anaesthetic and suturing $\mathrm{p}<0.0001$ (table 3).

The median time taken to complete the procedure was similar in all groups; 18 minutes (range 11-25) in the flumazenil and midazolam group, 20 minutes (range 10-25) in the midazolam only group and 20 minutes (range 10-65) in the ketamine group. The increased range in the latter group was entirely attributable to increased time in the two children needing supplemental ketamine (65, 40 minutes).

Parents showed a preference for sedation with ketamine (table $4, \mathrm{p}=0.10$ ). The overall satisfaction with the attendance may have been positively effected by the presence of a senior doctor. During the procedure 13 (32\%) parents felt faint or upset in the midazolam study group compared with $16(34 \%)$ in the ketamine group. No child of any age in either 


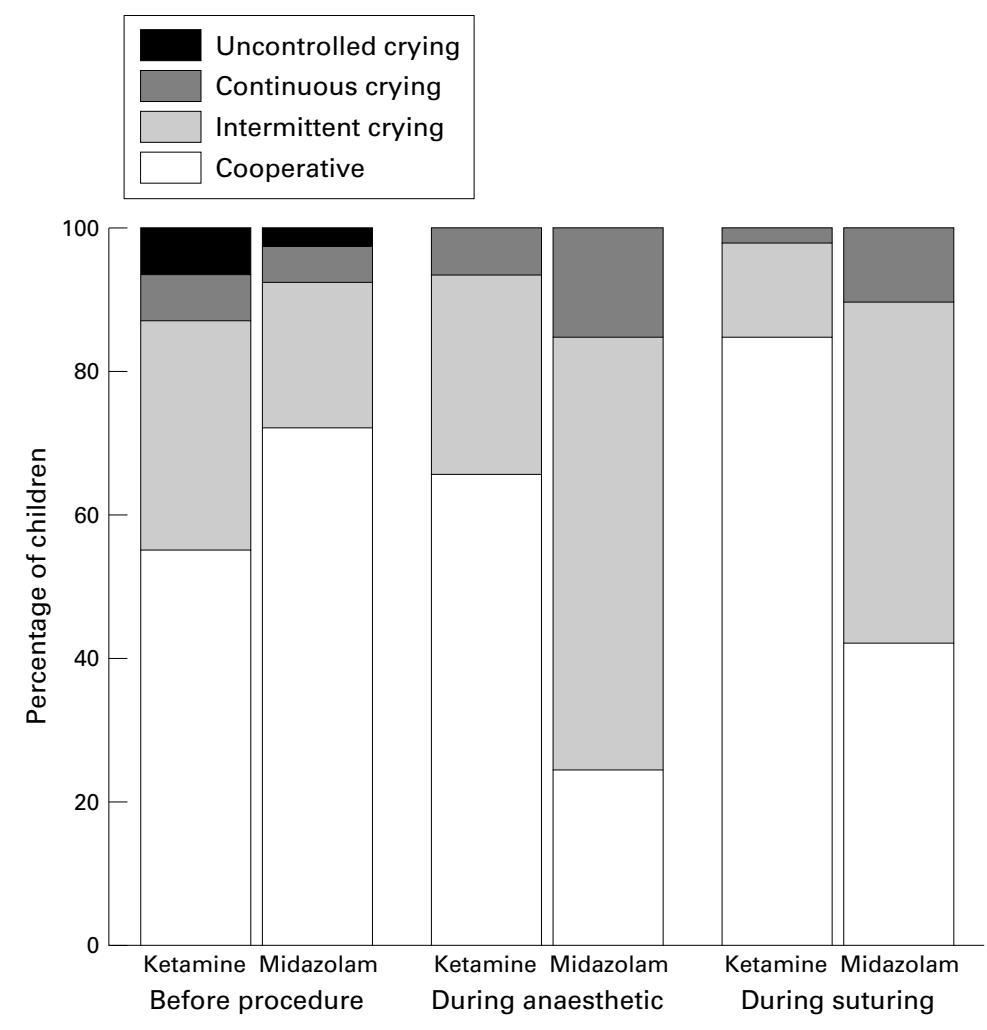

Figure 2 Comparison of behaviour between ketamine and midazolam groups.

Table 3 Degree of restraint needed, ketamine $(n=47)$ versus midazolam $(n=40)$

\begin{tabular}{llllll}
\hline & \multicolumn{2}{l}{$\begin{array}{l}\text { During local anaesthetic } \\
\text { administration }\end{array}$} & & \multicolumn{2}{l}{ During suturing } \\
\cline { 2 - 3 } Areas restrained & Ketamine & Midazolam & & Ketamine & Midazolam \\
\hline 0 & $27(57)$ & $2(5)$ & & $32(68)$ & $5(12)$ \\
1 & $13(28)$ & $17(42)$ & & $12(26)$ & $19(48)$ \\
2 & $5(11)$ & $15(38)$ & & $1(2)$ & $10(25)$ \\
3 & $2(4)$ & $6(15)$ & & $2(4)$ & $6(15)$ \\
Ketamine $v$ midazolam & & $\mathrm{p}<0.0001$ & & $\mathrm{p}<0.0001$ \\
\hline
\end{tabular}

Values are number (\%).

Table 4 Degree of parent satisfaction with $A \mathcal{E} E$ attendance, ketamine $(n=47)$ versus midazolam $(n=40)$

\begin{tabular}{lll}
\hline Parental satisfaction & Ketamine & Midazolam \\
\hline Worse than expected (\%) & $1(2)$ & $6(15)$ \\
Same as expected (\%) & $9(19)$ & $8(20)$ \\
Better than expected (\%) & $37(79)$ & $26(65)$ \\
\hline $\mathrm{p}=0.1$. & &
\end{tabular}

the ketamine or midazolam groups remembered the suturing.

In the 47 ketamine cases in this study the incidence of vomiting was one during recovery and four at home (five children, 10.6\%). The median time of discharge was 102 minutes.

No children in the study had nightmares or a disturbed night. However, one mother from the midazolam group (without flumazenil) stated that her child had shown aggressive behaviour at home.

\section{Discussion}

The older the adult the more sensitive the subject is to the effect of midazolam..$^{15}$ In children this observation is even more pronounced, the plasma clearance of midazolam in children is higher than in adults by a factor of 2 to 3 and this more rapid metabolic turnover of the drug should be remembered when considering the paediatric dose. ${ }^{12}{ }^{16}$ When evaluating the doses of midazolam given by different routes it is important to consider the bioavailability via these routes.

Oral midazolam is subject to incomplete absorption, there is a significant "first pass" metabolism with a bioavailability of $15 \%{ }^{12}$ at higher doses and reduced gastric emptying in an anxious child may delay its effect. The bioavailability via the rectal route is as low $18 \%,{ }^{12}$ and has an obvious drawback in administration to an uncooperative child. The bioavailability of the intranasal route has been quoted as $55 \%$ and $57 \%{ }^{16}$ and the half life is similar to the intravenous one. ${ }^{16}$. The intramuscular route has been described previously in children, ${ }^{17}$ as a premedication at a dose of $0.2 \mathrm{mg} / \mathrm{kg}$ and the bioavailability is $87 \% .^{12}$. Thus $0.4 \mathrm{mg} / \mathrm{kg}$ intramuscularly is equivalent to approximately 2 $\mathrm{mg} / \mathrm{kg}$ orally.

Midazolam has a potent amnesic effect, but has no effect on memory before the drug being given. ${ }^{13}$. At a dose of $0.2 \mathrm{mg} / \mathrm{kg}$ intranasal midazolam only $29 \%$ of children undergoing dental treatment had recall ${ }^{18}$ and at dose of 0.5 $\mathrm{mg} / \mathrm{kg}$ orally only $34 \%$ had total recall. ${ }^{2}$ As the main advantage of midazolam is its amnesic effect then the dose chosen should guarantee this effect. Our previous study ${ }^{1}$ showed that a dose of $0.5 \mathrm{mg} / \mathrm{kg}$ intranasally did indeed provide total amnesia. Hence we would expect that a dose of $1 \mathrm{mg} / \mathrm{kg}$ orally or $0.2 \mathrm{mg} / \mathrm{kg}$ intramuscularly would provide amnesia for the procedure in all children (based on the bioavailability of the routes). This would of course need to be validated in a clinical trial. Increasing the dose further has little advantage as restraint will still be needed and it can also delay the time when the child is ready for discharge, unless flumazenil is given.

Flumazenil certainly reduced the discharge time and may have an effect on the degree of agitation during recovery and behavioural problems at home. Jones et $a l^{19}$ in a randomised, double blind study involving 40 children found that intravenous flumazenil rapidly antagonised midazolam induced hypnosis in children and was not associated with any episodes of resedation. The anxiety concerning resedation can be tackled after reviewing the pharmacokinetics of midazolam and flumazenil. Jones $e t a l^{20}$ found the mean half life of midazolam in 12 children $5-9$ years to be 1.8 hours. Payne $e t a l^{12}$ studied midazolam in eight children (3-10 years) finding the half life to be 1.17 hours compared with $1.5-2.5$ hours in young adults and 5-6 hours in elderly men. The efficacy of flumazenil is dependent upon the timing of administration, the dose of both agonist and antagonist given and the pharmacokinetics of both drugs. Flumazenil itself has a shorter half life in children ( 35 minutes) than in adults (60-77 minutes). ${ }^{20}$ Clinically significant resedation although a potential problem in elderly patients is most unlikely to occur in young children. ${ }^{19}{ }^{20}$ Flumazenil via the intranasal route seems to work, but needs to be available in a more concentrated solution. In addition the drug is still relatively expensive. 
The pre-sedation behaviour of the midazolam group as judged by the nurse was only slightly different from the ketamine group despite the doctor having excluded combative children from the former. The effect of these exclusions would put more combative children in the ketamine group. Despite this, in the midazolam group the degree of crying and restraint needed was greater both during the local anaesthetic administration and the suturing.

The incidence of vomiting after ketamine in our initial paper ${ }^{1} 18 \%$ was unexpectedly high. In the 47 ketamine cases in this study the incidence of vomiting was one during recovery and four at home (five children, 10.6\%). The median time of discharge was 102 minutes. We believe that after the results of the initial study ${ }^{1}$ were known nursing staff were not attempting to mobilise these children as early and this reduced the incidence of vomiting.

With the cooperation of another centre we are now investigating a lower dose of ketamine $(2 \mathrm{mg} / \mathrm{kg})$ to ascertain its efficacy, side effect profile and time when ready for discharge.

Considering the available literature on the subject parents should be offered the option of sedation for their children before suturing. The days of wrapping the child up and, "getting on with it " should be put firmly in the past. The psychological trauma of using Brutacaine ${ }^{1}$ (restraint) is upsetting for all at the time and may remain with the patient into adulthood as "needle phobia". ${ }^{21}{ }^{22}$ It is estimated that about $10 \%$ of the adult population have a phobia about needles, ${ }^{23}$ which can cause the affected person to decline necessary treatment. Injection is the commonest route for childhood immunisation, so to reject the use of ketamine because it involves the use of a needle is not logical. Indeed without sedation it is often the restraint needed during the suturing that both parent and child remembers. The following recent case is quoted as an example. A professional 34 year old man with a phobia about hospitals was visibly anxious about undergoing medical investigations. When asked whether he knew why he might have this phobia, he pointed to a scar on his hand, "When I was 6 years old I was held down and stitched up".

In conclusion, if sedation is indicated low dose intramuscular ketamine remains the drug of choice in our department for the suturing of young children. If midazolam is used then a dose and route needs to be chosen that will ensure total amnesia for the procedure (1 $\mathrm{mg} / \mathrm{kg}$ orally, $0.5 \mathrm{mg} / \mathrm{kg}$ intranasally or 0.2 $\mathrm{mg} / \mathrm{kg} \mathrm{im}$ ), increasing the dose further is of lit- tle benefit. At these doses resedation although a potential problem in elderly patients is most unlikely to occur in young children. Intranasal flumazenil will reduce the time ready for discharge and may reduce the paradoxical hyperagitation sometimes seen after the procedure. However, in view of the dilute concentration available and cost, its use is not currently practical.

The authors thank Mr P McGlone, Nuffield Science Bursary, Statistics Department, Lancaster University for his help.

Funding: Roche Pharmaceuticals Ltd provided a grant of $£, 500$ and the cost of flumazenil used in the study.

Conflicts of interest: none.

1 McGlone R, Ranasinghe S, Durham S. An alternative to "Brutacaine": a comparison of low dose intramuscular ketamine with intranasal midazolam in children before suturing. F Accid Emerg Med 1998;15:231-6.

2 Davies F, Waters $M$. Oral midazolam for conscious sedation of children during minor procedures. 7 Accid Emerg Med 1998;15:244-8.

3 Theroux M, West D. Efficacy of intranasal midazolam in facilitating suturing of lacerations in preschool children in the emergency department. Paediatrics 1993;91:624-7.

4 Yealy D, Ellis J. Intranasal midazolam as a sedative for children during laceration repair. Am f Emerg Med 1992;10 $584-7$.

5 Connors K, Terndrup T. Nasal versus oral midazolam for sedation of anxious children undergoing laceration repair. Ann Emerg Med 1994;24:1074-9.

6 Abrams R, Morrison J. Safety and effectiveness of intranasal administration of sedative medications (ketamine, midazolam or sufentanil) for urgent brief paediatric dental procedures. Anaesthesia Progress 1993;40:63-6.

7 Geller E, Niv D. The use of flumazenil in the treatment of 34 intoxicated patients. Resuscitation 1988;16:857-62.

8 Weinbroum A, Halpern P, Geller E. The use of flumazenil in the management of acute drug poisoning - a review. Intenthe management of acute drug
sive Care Med 1991;17:S32-8.

9 Lopez-Herce J, Lopez de Sa E. Reversal of midazolam sedation with rectal flumazenil in children. Crit Care Med 1994;
tion 22:1204-5.

10 Rosario M, Alves I. Does intranasal flumazenil work? [Abstract]. Gastrointest Endosc 1993;39:269.

11 Lugo R, Fishbein M. Complication of intranasal midazolam. [Letter]. Paediatrics 1993;92:638.

2 Payne J G, Mattheyse F J. The pharmacokinetics of midazolam in paediatric patients Eur f Clin Pharmacol 1989;37:267-72.

13 Twersky R, Hartung J. Midazolam enhances anterograde but not retrograde amnesia in paediatric patience. Anesthesiology 1993;78:51-5

14 Green G, Nakamura R, Johnson E. Ketamine sedation for paediatric procedures: part 1, a perspective series. Ann Emerg Med 1990;19:1024-32.

15 Nishiyama T, Matsukawa T, Hanaoka $K$. The effects of age and gender on the optimal premedication dose of intramuscular midazolam. Anesth Analg 1998;86:1103-8.

16 Rey E, Delaunay L. Pharmacokinetics of midazolam in children: comparative study of intranasal and intravenous

17 Taylor MB, Vine PR. Intramuscular midazolam premedication in young children. Anaesthesia 1986;41:21-6.

8 Kupietzky A, Holan G. Intranasal midazolam better at effecting amnesia after sedation than oral hydroxyzine: a pilot study. Pediatr Dent 1996;18:32-4.

19 Jones RD, Lawson AD, Andrew LJ. Antagonism of the hypnotic effect of midazolam in children: a randomised, double-blind study of placebo and flumazenil administered after midazolam-induced anaesthesia. Br f Anaesth 1991; 66:660-6.

20 Jones RD, Chan K, Roulson CJ. Pharmacokinetics of flumazenil and midazolam. Br f Anaesth 1993;70:286-92.

21 Trigwell PJ. Iatrogenic needle phobia. [Letter]. $\mathrm{Br}$ Dent $\mathcal{F}$ 1993:174:158.

22 Kleinknecht RA. Acquisition of blood, injury, and needle fears and phobias. Behav Res Ther 1994;32:817-23.

23 Hamilton JG. Needle phobia: a neglected diagnosis; clinical review. F Fam Pract 1995;41:2. 